\title{
Perinatal Depression in Men During Partner's Pregnancy: A Cross- Sectional Study in Chugoku Region of Japan
}

\section{Akemi Mitani ${ }^{1}$, Mayumi Ono ${ }^{2}$, Junko Maeda ${ }^{2}$ and Kumiko Kido ${ }^{3 *}$ (1)}

${ }^{1}$ Yamaguchi Prefectural University, Post Undergraduate Program in Midwifery,6-2-1 Sakurabatake Yamaguchi City, Yamaguchi, Japan

${ }^{2}$ Tokuyama Central Hospital, 1-1 Kodacho Shunan City, Yamaguchi, Japan

${ }^{3}$ Kagawa Prefectural University of Health Sciences, 281-1 Murecho Hara Takamatsu City, Kagawa, Japan

\section{Abstract}

Objective: This study aimed to investigate paternal depression occurring during a partner's pregnancy in the Chugoku region of Japan, as well as to examine the factors associated with paternal depression and its possible relevance to the attachment with the child.

Methods: This cross-sectional study used the Patient Health Questionnaire-9 (PHQ-9) to assess depression in men. Sociodemographic details and background factors from previous studies on paternal depression included. In particular, relevant scales were used to assess occupational stress, occupational satisfaction, marital relationship, and mother-to-infant bonding (Japanese version of the Mother-to-Infant Bonding Scale). The participants were 64 men whose partners were in their third trimester of pregnancy. Descriptive statistics were calculated and subsequently analyzed by bivariate and multivariate statistical analysis using IBM SPSS ${ }^{\circ}$ Statistics version 24.0 and EZR [1], with $\mathrm{P}<0.05$, considered statistically significant.

Results: Twelve fathers (18.75\%, 95\% CI: 10.1-30.5\%) had greater than mild depression on the PHQ-9. The health status of the child, occupational stress, and marital relationships were associated with depression in men $(\mathrm{p}<0.05)$. The depression group had significantly higher occupational stress, and poor marital relationships. The factors associated with depression with significant odds ratios were occupational stress and marital status.

Conclusion: In the Chugoku region, depression among fathers whose partners were pregnant was as much as in mothers. However, the specific factor associated with paternal depression appeared to be occupational stress and marital relationships. The findings of this study provide a basis for considering interventions for perinatal paternal depression.

\section{Introduction}

Glasser and Lerner-Geva reported a prevalence of perinatal paternal depression ranging from $2.3-8.4 \%$ in the meta-analysis [2]. In Japan, Takehara reported a prevalence of depression among $9.7 \%$ of fathers, at 20 weeks of gestation in Aichi Prefecture [3]; in a similar regional study, Suto et al. reported a prevalence of $17 \%$ during pregnancy [4] Additionally, Konishi et al. reported that the prevalence of prenatal depression among fathers with pregnant partners was between $3.7 \%$ and $10.3 \%$ [5]. Whereas these studies were conducted in a particular region of Japan, Kido et al. found, from a nationwide web-based survey, that $31.3 \%$ (95\% CI: $27.3-35.7 \%)$ of men with pregnant partners suffered from prenatal depression [6]. They also reported prevalence rates in different areas of Japan; Chugoku region (it consists of five prefectures (Tottori, Shimane, Okayama, Hiroshima and Yamaguchi) in the most western part of mainland in Japan) having the highest score out of any region with a median Edinburgh Postnatal Depression Scale (EPDS) of 11. The EPDS used in Kido et al's study considered a cut-off score of 13 points or more. It was assumed that EPDS scores were generally higher in the Chugoku region, although the proportion of scores above 13 was small [6].

Whereas previous assessments of perinatal paternal depression have used the EPDS, the scale was developed for mothers [7]. As the nature of depressive symptoms in men has been reported to be different from those in women [8], questions have been raised about the reliability of the EPDS as a measure of perinatal depression in fathers [9]. Alternative to the EPDS as an instrument for perinatal depression in fathers, there are studies using the Patient Health Questionnaire-9 (PHQ-9) as a general depression screening scale 5].

\section{Publication History:}

Received: February 03, 2022 Accepted: February 14, 2022 Published: February 16, 2022

\section{Keywords:}

Perinatal paternal depression Patient Health Questionnaire-9, Occupational stress, Rural area Ministry of Health, Labour and Welfare (MHLW) of Japan has been encouraging fathers to avail of childcare leave. Starting April 2022, the Act on Childcare Leave, Caregiver Leave, and Other Measures for the Welfare of Workers Caring for Children or Other Family Members will be amended to allow men four weeks of postnatal leave, out of the eight weeks they are entitled to after their partner delivers a baby [10]. This implies that fathers' involvement in childcare is being increasingly encouraged nationally; the prevalence of perinatal paternal depression may rise as a result of this new policy.

Untreated paternal depression occurring during the perinatal period has been reported to increase the risk of specific mental disorders among school-aged children, twice as significantly. In Japan, Nishigori et al. reported on paternal perinatal depression and child attachment [11]. Postnatal depression in mothers has been identified as an issue that required addressing in Japan, mothers has been approached with a questionnaire to assess their feelings towards their babies using the Japanese version of the Mother-Infant Bonding Scale (MIBS-J) [12]. Because, perinatal depression can be associated with

"Corresponding Author: Prof. Kumiko Kido, Kagawa Prefectural University of Health Sciences, 281-1 Murecho Hara Takamatsu city, Kagawa, Japan, Tel: +8187-870-1212; E-mail: kkumiko0305@gmail.com

Citation: Mitani A, Ono M, Maeda J, Kido K (2022) Perinatal Depression in Men During Partner's Pregnancy: A Cross-Sectional Study in Chugoku Region of Japan. Int J Nurs Clin Pract 9: 354. doi: https://doi.org/10.15344/2394-4978/2022/354

Copyright: (c) 2022 Mitani et al. This is an open-access article distributed under the terms of the Creative Commons Attribution License, which permits unrestricted use, distribution, and reproduction in any medium, provided the original author and source are credited. 
negative feelings towards baby, which increase the potential risk of neglect or abuse of the baby in both mother and father [12]. Postnatal depression in mothers was identified as an issue that required addressing in Japan, mothers were approached with a questionnaire to assess their feelings towards their babies using the Japanese version of the Mother-Infant Bonding Scale (MIBS-J) [12]. Although the scale have been used to assess mothers during their pregnancy, no studies have been reported that assess fathers during their partners' pregnancy. Paternal depression should be treated as a crucial problem that negatively impact children's mental health and thus, requires urgent intervention [13].

This study aimed to investigate paternal depression occurring during a partner's pregnancy in the Chugoku region of Japan, as well as to examine the factors associated with paternal depression and its possible relevance to attachment with the child. In this study, instead of the EPDS, a general depression scale was used to assess perinatal paternal depression. The findings of this study provide a basis for considering interventions for perinatal paternal depression.

\section{Methods}

\section{Study design}

This cross-sectional study examined the prevalence of depression and associated factors among men whose partners were pregnant in a rural area, Chugoku region, in Japan.

\section{Measurement for paternal depression}

The PHQ-9 [14] was used to assess depression in men. The PHQ9 , which has previously been reported to be available for screening the prevalence of perinatal depression in men, used in this study [5] The PHQ-9 comprises a nine-item scale to assess depression levels. The symptom assessment was based on the existence of symptoms for each question within a week, with the score distributed as follows: never: 0 points, a few days: 1 point, more than half of the week: 2 points, and almost every day: 3 points. The total score ( $0-27$ points) was calculated. It also assesses depressive severity, based on the total score of questions 1 to 9: 0-4: normal to minor; 5-9: mild; 10-14: moderate; 15-19: moderate to severe; and 20-27: severe.

\section{The risk factors associated with perinatal depression for fathers}

The following sociodemographic details and main background factors, considered from previous studies on paternal depression, were collected: number of children; unexpected pregnancy; own (partner's) mental health history; family bereavement as a life event; health status of children; and economic status [15-17]. Additionally, the questionnaire asked about marital status, occupational stress, occupational satisfaction, and feelings toward the child that affect men's perinatal depression. The questions on the marital relationship consisted of the following six items: "building trust in each other," "mutual understanding," "spending enough time as a couple," "having many conversations as a couple," "respecting some hobbies and activities," and "doing my best at parenting and housework". All of these were examined using a four-point Likert scale ranging from "I don't feel it at all" to "I always feel it strongly." The questions on occupational stress consisted of the following 11 items: "Excessive responsibility," "no one talks with me at work," "long working hours," "not suited to the job," "difficulty coping with information technology and innovation," "uncertainty about the future of the company," "fear of redundancy or bankruptcy," "excessive emphasis on work performance," "heavy workload," "uncomfortable working environment," "difficult working relationships' uncomfortable working environment", "difficulties in interpersonal relations at work". All of these were examined on a four-point Likert scale, ranging from "I don't feel at all" to "I always feel strongly." A high score indicates lower stress at work, and a lower score indicates a better relationship with the spouse. Occupational satisfaction is constructed from the following seven items: "Salary and wages," "amount of week off and holiday," "work contents," "discretion of the work," "evaluation and compensation,"“work/ life balance," and "the amount of paperwork to take home". All of these were examined on a five-point Likert scale, ranging from "I completely satisfied" to "I totally dissatisfied". A lower score indicates a higher level of job satisfaction. The Japanese version of Mother to Infant Bonding Scale (MIBS-J) [12] was used to question the feelings towards their baby. It consists of 10 items, rated on a scale of 0 to 3 , with higher scores indicating stronger negative feelings toward the baby. The scale assesses attachment and rejection/anger toward the baby.

\section{Sample size}

The number of births per year in the rural area was calculated to be approximately 8,000 (year 2021), with a confidence level of $90 \%$, a tolerability of $10 \%$, and a response ratio of 0.5 , resulting in a sample size of 67.

\section{Subjects, procedures, and the exclusion criteria}

The participants were 64 men whose partners were in their third trimester of pregnancy. All data were obtained from the male partners of pregnant women who visited the obstetrics and gynecology department of a general hospital in a regional city (population $140,000)$ in Japan. Participation in the study was voluntary. In terms of exclusion criteria, foreign nationals living in Japan were excluded because their language skills may not allow them to fully understand the questions.

\section{Analysis methods}

Descriptive statistics were calculated and subsequently analyzed by bivariate and multivariate statistical analysis using IBM SPSS ${ }^{\circ}$ Statistics version 24.0 and EZR [1], with P-value $<0.05$, considered statistically significant. Also, the PHQ-9 cut-off were used to compare the two groups, PHQ-9 $<4$ (non-depression group) and PHQ-9 $>4$ (depression group).

\section{Ethical considerations}

A midwife working in the Department of Obstetrics and Gynecology of the General Hospital explained the significance, purpose, and methods of the study to the participants. It was also explained that refusal to participate would not affect them in any way. In addition, the privacy of the respondents was protected by asking them to complete the questionnaire anonymously to prevent the researcher from identifying them. The study was approved by the Ethical Committee of the Kagawa Prefectural University of Health Sciences (approval number 274) and the Ethical Review Boards of the hospitals where the data were collected (approval number K40220210203).

\section{Results}

\section{Depression and feelings about the baby}

The prevalence of perinatal paternal depression and the negative feelings towards baby were showed Table 1 . Twelve participants 
Citation: Mitani A, Ono M, Maeda J, Kido K (2022) Perinatal Depression in Men During Partner's Pregnancy: A Cross-Sectional Study in Chugoku Region of Japan. Int J Nurs Clin Pract 9: 354. doi: https://doi.org/10.15344/2394-4978/2022/354

Page 3 of 6

(18.75\%, 95\% CI: 10.1-30.5\%) had greater than mild depression on the PHQ-9. Thirty-six (56.3\%, 95\%CI: 25.40 - 37.10\%) had an MIBS-J score of $>3$.

\begin{tabular}{|l|l|l|}
\hline & $\mathrm{N}(\%)$ & $95 \%$ Confidence interval (CI) \\
\hline PHQ-9 $>4$ & $12(18.75)$ & $10.10-30.50(\%)$ \\
\hline MIBS-J $>3$ & $36(56.3)$ & $25.40-37.10(\%)$ \\
\hline
\end{tabular} $\begin{aligned} & \text { Table 1: The prevalence of perinatal paternal depression and the } \\
& \text { negative feelings towards baby. } \\
& \text { A PHQ-9 cut-off of } 4 \text { points or more, with a risk of depression. MIBS-J } \\
& \text { points of three or more negative feelings towards the baby. }\end{aligned}$

Demographics of the participants showed Table 2. Sixty-four fathers completed the survey although 67 were invited to participate (the valid responses were $95.5 \%$ ). The demographics of the fathers were compared between two groups: PHQ- $9<4$ (non-depression group) and PHQ-9 $>4$ (depression group). PHQ-- $>4$ (depression group) were significantly more frequently reported poor about health status of the child.

\section{Occupational stress, satisfaction, and marital relationships}

The level of occupational stress of the subjects is shown in Table 3, and satisfaction with their work is shown in Table 4 . The marital status of couples is shown in Table 5 .

\begin{tabular}{|c|c|c|c|c|c|}
\hline \multirow[t]{2}{*}{ Parameter } & \multirow[t]{2}{*}{$\mathrm{N}=64$} & All & $\begin{array}{l}\text { PHQ-9 > } \\
\mathrm{N}=12\end{array}$ & $\begin{array}{l}\text { PHQ-9 }<4 \\
\mathrm{~N}=52\end{array}$ & \multirow[t]{2}{*}{$\mathrm{P}$} \\
\hline & & \multicolumn{3}{|c|}{ Median (max-min) } & \\
\hline Age of the father & & $33.0(19-55)$ & $31(19-42)$ & $34(25-55)$ & 0.086 \\
\hline Partners' age & & $32.5(19-43)$ & $31.5(19-43)$ & $33.5(25-43)$ & 0.105 \\
\hline Partner's gestational week & & $34.0(30-40)$ & $34(30-35)$ & $33(30-40)$ & 0.530 \\
\hline Working time (hours) & & $8.0(7-13)$ & $10(7.5-13)$ & $8(7.0-12)$ & 0.330 \\
\hline MIBS-J & & $3(0-11)$ & $3(1-7)$ & $3(0-11)$ & 0.312 \\
\hline \multirow[t]{2}{*}{ PHQ-9 } & & $1(0-10)$ & $7(6-10)$ & $1(0-4)$ & $0.000^{*}$ \\
\hline & \multicolumn{4}{|c|}{$\mathrm{N}(\%)$} & $\mathrm{P}$ \\
\hline \multicolumn{6}{|l|}{ First time baby } \\
\hline Yes & $33(51.6)$ & & $6(50.0)$ & $27(51.9)$ & \multirow[t]{2}{*}{1.000} \\
\hline No & $31(48.4)$ & & $6(50.0)$ & $25(48.1)$ & \\
\hline \multicolumn{6}{|l|}{ Family structure } \\
\hline Nuclear families & $60(93.8)$ & & $12(100.0)$ & $48(92.3)$ & \multirow[t]{2}{*}{-} \\
\hline Extended families & $4(6.3)$ & & $0(0)$ & $4(7.7)$ & \\
\hline \multicolumn{6}{|l|}{ Employment status } \\
\hline Full-time & $64(100)$ & & $12(100.0)$ & $52(100.0)$ & \multirow[t]{2}{*}{-} \\
\hline Part-time/none & $0(0)$ & & $0(0)$ & $0(0)$ & \\
\hline \multicolumn{6}{|l|}{ Marriage } \\
\hline Yes & $64(100)$ & & $12(100.0)$ & $52(100.0)$ & \multirow[t]{2}{*}{-} \\
\hline No & $0(0)$ & & $0(0)$ & $0(0)$ & \\
\hline \multicolumn{6}{|l|}{ Unexpecting pregnancy } \\
\hline Yes & $7(10.9)$ & & $2(16.7)$ & $5(9.6)$ & \multirow[t]{2}{*}{0.607} \\
\hline No & $57(89.1)$ & & $10(83.3)$ & $47(90.4)$ & \\
\hline \multicolumn{6}{|l|}{ Live together } \\
\hline Yes & $61(95.3)$ & & $12(100.0)$ & $49(94.2)$ & \multirow[t]{2}{*}{-} \\
\hline No & $3(4.7)$ & & $0(0)$ & $3(5.8)$ & \\
\hline \multicolumn{6}{|c|}{ Economic anxiety(Subjective) } \\
\hline Yes & $27(42.2)$ & & $6(50.0)$ & $21(40.4)$ & \multirow[t]{2}{*}{0.747} \\
\hline No & $37(57.8)$ & & $6(50.0)$ & $31(59.6)$ & \\
\hline \multicolumn{6}{|l|}{ Health statusof child } \\
\hline Good & $52(81.3)$ & & $7(58.3)$ & $45(86.5)$ & \multirow[t]{2}{*}{$0.039^{*}$} \\
\hline Poor & $12(18.8)$ & & $5(41.7)$ & $7(13.5)$ & \\
\hline \multicolumn{6}{|c|}{ Bereavement of the family members } \\
\hline Yes & $6(9.4)$ & & $2(16.7)$ & $4(7.7)$ & 0.312 \\
\hline No & $58(90.6)$ & & $10(83.3)$ & $48(92.3)$ & \\
\hline \multicolumn{6}{|c|}{ Health problems(of himself) } \\
\hline Yes & $2(3.1)$ & & $0(0)$ & $2(3.8)$ & \multirow[t]{2}{*}{-} \\
\hline No & $62(96.9)$ & & $12(100.0)$ & $50(96.2)$ & \\
\hline Health problems(of his par & tner) & & & & \\
\hline Yes & $4(6.3)$ & & $1(8.3)$ & $3(5.8)$ & 0.574 \\
\hline No & $60(93.7)$ & & $11(91.7)$ & $49(94.2)$ & \\
\hline
\end{tabular}

Table 2: Demographics of the participants.

The chi-square test was not performed due to containing zeros in a cell.

$\mathrm{P}=\mathrm{P}$ value, ${ }^{*}: \mathrm{P}<0.05$

Each parameter was compared in two groups: PHQ-9 $<4$ (non-depression group) and PHQ-9 $>4$ (depression group). 
Citation: Mitani A, Ono M, Maeda J, Kido K (2022) Perinatal Depression in Men During Partner's Pregnancy: A Cross-Sectional Study in Chugoku Region of Japan. Int J Nurs Clin Pract 9: 354. doi: https://doi.org/10.15344/2394-4978/2022/354

Page 4 of 6

\section{Depression-related factors}

The results of the Mann-Whitney $U$ test showed significant differences in the scores of occupational stress and marital relationship in the results of the comparison between the depressionand nondepression groups (Table 6). The depression group had significantly higher occupational stress, and marital relationships were also poor.

The factors associated with depression with significant odds ratios (OR) were occupational stress and marital status (Table 7).

\section{Discussion}

\section{The prevalence of paternal depression}

In Japan, depression among fathers during their spouse's pregnancy has been reported to be between $3.7 \%$ and $31.3 \%$ [3-6]. In the present study, 12 men showed depressive symptoms when their partners' pregnancy was identified (PHQ-9 $>4=18.75 \%, 95 \%$ CI: $10.1-30.5 \%$ ). In this study, the PHQ-9 was used to assess perinatal depression in fathers. In a rural area of Japan, it was revealed that less than $20 \%$

\begin{tabular}{|l|l|l|l|l|l|}
\hline \multicolumn{3}{|c|}{$\mathrm{N}(\%)$} & $\mathrm{N}=64$ & Median (max-min) \\
\hline Items & 1 & 2 & 3 & 4 & \\
\hline 1. Heavy responsibility & $7(10.9)$ & $27(42.2)$ & $25(39.1)$ & $5(7.8)$ & $2(1-4)$ \\
\hline 2. Having no one talking with me at the workplace & $0(0.0)$ & $15(23.4)$ & $29(45.3)$ & $20(31.3)$ & $3(2-4)$ \\
\hline 3. Working long hours & $9(14.1)$ & $16(25.0)$ & $28(43.8)$ & $11(17.2)$ & $3(1-4)$ \\
\hline 4. Not fit for the job & $1(1.6)$ & $10(15.6)$ & $41(64.1)$ & $11(18.8)$ & $3(1-4)$ \\
\hline 5. Difficulty responding to informatization & $3(4.7)$ & $14(21.9)$ & $29(45.3)$ & $18(28.1)$ & $3(1-4)$ \\
\hline 6. Anxiety of the company's future & $5(7.8)$ & $25(39.1)$ & $25(39.1)$ & $9(14.1)$ & $3(1-4)$ \\
\hline 7. Anxiety of being fired/going bankrupt & $4(6.3)$ & $15(23.4)$ & $32(50.0)$ & $13(20.3)$ & $3(1-4)$ \\
\hline 8. Excessive emphasis on work performance & $9(14.1)$ & $13(20.3)$ & $34(53.1)$ & $8(12.5)$ & $3(1-4)$ \\
\hline 9. Heavy workload & $9(14.1)$ & $21(32.8)$ & $28(43.8)$ & $6(9.4)$ & $3(1-4)$ \\
\hline 10. Uncomfortable working environment & $4(6.3)$ & $8(12.5)$ & $37(57.8)$ & $15(23.4)$ & $3(1-4)$ \\
\hline 11. Distressing relationships at workplace & $4(6.3)$ & $10(15.6)$ & $35(54.7)$ & $15(23.4)$ & $3(1-4)$ \\
\hline Total score(min-max) & & & & & $31(18-44)$ \\
\hline
\end{tabular}

Table 3: Occupational stress.

The meaning of the scores is as follows: 1 , feeling strongly; 2 , feeling a little; 3 , not feeling so strongly; and 4 , not at all.The total scoreranges from 11 (min) to $44(\max )$.

\begin{tabular}{|l|l|l|l|l|l|l|}
\hline & \multicolumn{3}{|c|}{$\mathrm{N}(\%)$} & $\mathrm{N}=64$ & Median (max-min) \\
\hline Items & 1 & 2 & 3 & 4 & 5 & \\
\hline 1.Salary and wages & $6(9.4)$ & $19(29.7)$ & $14(21.9)$ & $15(23.4)$ & $10(15.6)$ & $3(1-5)$ \\
\hline 2.The amount of week off and holiday & $12(18.8)$ & $22(34.4)$ & $15(23.4)$ & $7(10.9)$ & $8(12.5)$ & $2(1-5)$ \\
\hline 3.Work contents & $9(14.1)$ & $26(40.6)$ & $22(34.4)$ & $6(9.38)$ & $1(1.6)$ & $2(1-5)$ \\
\hline 4.Discretion of the work & $6(9.4)$ & $19(29.7)$ & $30(46.9)$ & $7(10.9)$ & $2(3.1)$ & $3(1-5)$ \\
\hline 5.Evaluation and compensation & $9(14.1)$ & $22(34.4)$ & $24(37.5)$ & $5(7.8)$ & $4(6.3)$ & $3(1-5)$ \\
\hline 6.Work/life balance & $6(9.4)$ & $34(53.1)$ & $15(23.4)$ & $4(6.25)$ & $5(7.8)$ & $2(1-5)$ \\
\hline 7.The amount of paperwork to take home & $5(7.8)$ & $8(12.5)$ & $24(37.5)$ & $27(42.19)$ & $0(0)$ & $3(1-4)$ \\
\hline Total score(min-max) & & & & & & $19(7-31)$ \\
\hline
\end{tabular}

Table 4: Occupational satisfaction.

The meaning of the scores is as follows: 1 , extremely satisfied; 2 , fairly satisfied; 3 , half satisfied; 4 , not very satisfied; 5 , not at all. The total score ranges from 7 ( $\mathrm{min})$ to $35(\max )$.

\begin{tabular}{|l|l|l|l|l|l|}
\hline & \multicolumn{3}{|c|}{$\mathrm{N}(\%) 64$} & Median (max-min) \\
\hline Items & 1 & 2 & 3 & 4 & \\
\hline 1. Building trust in a mutual relationship & $23(35.9)$ & $35(54.7)$ & $5(7.8)$ & $1(1.6)$ & $2(1-4)$ \\
\hline 2. Mutual understanding & $28(43.8)$ & $31(48.4)$ & $4(6.3)$ & $1(1.6)$ & $2(1-4)$ \\
\hline 3. Having enough time with the marital partner & $20(31.3)$ & $34(53.1)$ & $9(14.1)$ & $1(1.6)$ & $2(1-4)$ \\
\hline 4. Having a lot of conversations with the marital partner & $29(45.3)$ & $24(37.5)$ & $11(17.2)$ & $0(0.0)$ & $2(1-3)$ \\
\hline 5. Respect for several hobbies and activity & $22(34.4)$ & $37(57.8)$ & $2(3.1)$ & $3(4.7)$ & $2(1-4)$ \\
\hline 6. Work hard at parenting and housework & $44(68.8)$ & $18(28.1)$ & $2(3.1)$ & $0(0.0)$ & $1(1-3)$ \\
\hline Total score(min-max) & & & & & $10(6-19)$ \\
\hline
\end{tabular}

Table 5: Marital relationships.

The meaning of the scores is as follows: 1 , absolutely yes; 2 , fairly yes; 3 , not so much; and 4, not at all. The total scores ranged from 6 (min) to 24 (max). 


\begin{tabular}{|l|l|l|l|}
\hline \multirow{2}{*}{} & PHQ-9 <4 & PHQ-9 $>4$ & \multirow{2}{*}{ P } \\
\cline { 2 - 3 } & \multicolumn{2}{|c|}{ Median (min-max) } & \multirow{2}{*}{} \\
\hline Occupational stress & $31.5(18-44)$ & $26.5(18-30)$ & $0.026^{*}$ \\
\hline Occupational satisfaction & $19.0(7-31)$ & $19.5(14-26)$ & 0.321 \\
\hline Marital relationships & $10.0(6-15)$ & $12.0(8-19)$ & $0.024^{*}$ \\
\hline MIBS-J & $3.0(0-11)$ & $3.0(1-7)$ & 0.312 \\
\hline
\end{tabular}

Table 6: Depression-related factors.

The Mann-Whitney U test was used to compare the two groups: PHQ$9<4$ (non-depression group) and PHQ-9 $>4$ (depression group). $\mathrm{P}=\mathrm{P}$ value, ${ }^{\star} \mathrm{P}<0.05$.

\begin{tabular}{|l|l|l|l|}
\hline Parameters & OR & $95 \% \mathrm{CI}$ & $\mathrm{P}$ \\
\hline Occupational stress & 0.805 & $0.663-0.977$ & $0.028^{*}$ \\
\hline Occupational satisfaction & 0.891 & $0.696-1.140$ & 0.358 \\
\hline Marital relationship & 1.590 & $1.080-2.340$ & $0.018^{*}$ \\
\hline $\begin{array}{l}\text { Health status of child } \\
\text { (Good=1, Poor=0) }\end{array}$ & 0.193 & $0.035-1.060$ & 0.058 \\
\hline MIBS-J & 0.803 & $0.5590-1.150$ & 0.237 \\
\hline
\end{tabular}

Table 7: The factors associated with the paternal depression.

$\mathrm{P}=\mathrm{P}$ value, ${ }^{\star} \mathrm{P}<0.05$.

The logistic regression model was constructed with the dependent variable as 'PHQ-9 score' and the explanatory variables as the total score of occupational stress, the total score of occupational satisfaction, and the total score of marital relationship', health status of child and the total score of MIBS-J.

of men show depressive symptoms during the perinatal period of their partners in this study. In a meta-analysis, Tokumitsu et al. reported that the prevalence of depression during pregnancy among Japanese women was $14.0 \%$ in the second trimester and $16.3 \%$ in the third trimester [18]. This highlights the need for the assessment of the mental health status of the father and the mother throughout the pregnancy. Mothers are required to receive regular prenatal examinations to ensure their mental health status and appropriate interventions; however, there is no such obligation for the fathers; therefore, their mental health conditions are less likely to be identified.

The EPDS has been used as a measure to assess perinatal depression in mothers; however, as mentioned above, it has been pointed out that the EPDS inadequately covers the depressive symptoms experienced by men. For instance, Massoudi et al. identified different factors of perinatal depression - worry, anxiety, and unhappiness - that were more frequently observed in fathers than in mothers [8]. Psouni et al. questioned the validity of the EPDS for men and attempted to develop a perinatal paternal depression scale [9]. Further research needs to be conducted in using or developing a scale that can assess specific perinatal depressive symptoms in fathers.

\section{Factors associated with perinatal paternal depression}

This study found that high occupational stress was one of the main factors associated with depression among perinatal fathers. In comparison with the normal group, men with PHQ-9 $>4$ had a median of eight working hours; in other words, they were not overworked. The occupational stress scale provides an assessment of work responsibilities, workload, and relationships at work. For men, feeling overburdened at work and having a poor working environment can affect their mental health. However, the association between having a baby and stress at work could not be confirmed.
Marital relationships have also been associated with paternal depression. In a couple in a bad relationship, the birth of a child may lead to poor parenting responsibilities; furthermore, if one of them undertakes a higher amount of burden than the other, the parenting environment may deteriorate. Thus, interventions to improve a couple's relationship are necessary, as poor parenting environment can have a negative impact on the child's development [13]. However, it is extremely difficult for health professionals to grasp the participants' marital relationships. It remains to be explored how and who assesses the couple's relationship and intervenes accordingly.

\section{Fathers' bonding with the child}

The MIBS-J has been validated by Yoshida et al. as an instrument for assessing the attachment of postpartum mothers to their children [12]. Whereas there is no cut-off score for MIBS-J, scores $>3$ indicate the need to be alert for the possibility of child abuse or neglect. However, research on the use of the MIBS-J as an instrument to assess fathers' attachment to their children during partners' pregnancy is lacking. Thus revealing that the majority of fathers $(56.3 \%, 95 \% \mathrm{CI}$ : $25.40-37.10 \%)$ had an MIBS-J score of $>3$, during their partner's pregnancy. Kitamura et al. found that failure of bonding with the child after delivery predicts maltreatment in mothers. Similarly, for fathers, their feelings toward their children may negatively affect their attitudes toward parenting in cases where the bonding with the child has not been well developed [19]. Whereas maternal bonding with the child occurs before childbirth, it remains unclear when the father's bonding with his child starts to emerge. To prevent maltreatment of the children by fathers, it is necessary to intervene from the period of pregnancy to develop and ensure father's bonding with the child. However, there is no opportunity to assess the father's feelings towards the child during the partner's pregnancy; therefore, it is essential to explore this aspect in further research.

\section{Conclusion}

In the Chugoku region of Japan, prevalence of depression among fathers whose partners were pregnant was similar to the prevalence in mothers. However, the specific factors associated with depression in men appeared to be occupational stress, marital relationships, and the health status of the child. However, this study has certain limitations, in that it was conducted in one rural area. Additional data need to be collected to ensure the reliability of the findings.

\section{Competing Interests}

The authors declare that they have no competing interests.

\section{Author's Contributions}

Mitani A and Kido K contributed to the idea of the study design, data analysis and drafting the manuscript.

Mayumi Ono and Junko Maeda collected and analyzed the data.

All authors read and agreed on the final manuscript.

\section{Funding}

This work was supported by JSPS KAKENHI Grant Number 18 K10399. 
Citation: Mitani A, Ono M, Maeda J, Kido K (2022) Perinatal Depression in Men During Partner's Pregnancy: A Cross-Sectional Study in Chugoku Region of Japan. Int J Nurs Clin Pract 9: 354. doi: https://doi.org/10.15344/2394-4978/2022/354

\section{References}

1. Kanda $Y$ (2013) Investigation of the freely available easy-to-use software 'EZR' for medical statistics. Bone Marrow Transplant 48: 452-458.

2. Glasser S, Lerner-Geva $L$ (2019) Focus on fathers: paternal depression in the perinatal period. Perspect Public Health 139: 195-198.

3. Takehara K, Suto M, Kakee N, Tachibana Y, Mori R, et al. (2017) Prenatal and early postnatal depression and child maltreatment among Japanese fathers. Child Abuse Negl 70: 231-239.

4. Suto M, Isogai E, Mizutani F, Kakee N, Misago C, et al. (2016) Prevalence and factors associated with postpartum depression in fathers: a regional longitudinal study in Japan. Res Nurs Health 39: 253-262.

5. Konishi M, Tachibana Y, Tang J, Takehara K, Kubo T, et al. (2016) A comparison of self-rated and female partner-rated scales in the assessment of paternal prenatal depression. Community Ment Health J 52: 983-988.

6. Kido K, Mitani A, Uemura Y, Okano M, Matsumura K, et al. (2020) The prevalence and relevant factors of paternal depression during a partners pregnancy in Japan. Int J Nurs Midwifery 12: 120-129.

7. Cox JL, Holden JM SR (1987) Detection of Postnatal Depression Development of the 10-item Edinburgh Postnatal Depression scale. $\mathrm{Br}$ Psychiatry 150: 782-786.

8. Massoudi $P$, Hwang CP, Wickberg B (2013) How well does the Edinburgh Postnatal Depression Scale identify depression and anxiety in fathers? A validation study in a population based Swedish sample. J Affect Disord 149: $67-74$

9. Psouni E, Agebjörn J,Linder H (2017) Symptoms of depression in Swedish fathers in the postnatal period and development of a screening tool. Scand J Psychol 58: 485-496.

10. Ministry of Health $L$ and W. the Act on Childcare Leave, Caregiver Leave and Other Measures for the Welfare of Workers Caring for Children or Other Family Members.

11. Nishigori $\mathrm{H}$, Obara T, Nishigori $\mathrm{T}$, Metoki H, Mizuno S, et al. (2020) Motherto-infant bonding failure and intimate partner violence during pregnancy as risk factors for father-to-infant bonding failure at 1 month postpartum: an adjunct study of the Japan Environment and Children's Study. J Matern Fetal Neonatal Med 33: 2789-2796.

12. Yoshida K, Yamashita H, Conroy S, Marks M, Kumar C, et al. (2012) A Japanese version of Mother-to-Infant Bonding Scale: factor structure, longitudinal changes and links with maternal mood during the early postnatal period in Japanese mothers. Arch Womens Ment Health 15: 343-352.

13. Gentile S, Fusco ML (2017) Untreated perinatal paternal depression: Effects on off spring. Psychiatry Res 252: 325-332.

14. Kroenke K, Spitzer RL, Williams JB (2001) The PHQ-9: validity of a brief depression severity measure. J Gen Intern Med 16: 606-613.

15. Nishigori H, Obara T, Nishigori T, Metoki, H, Mizuno S, et al. (2020) The prevalence and risk factors for postpartum depression symptoms of fathers at one and 6 months postpartum: an adjunct study of the Japan Environment \& Children's Study. J Matern Fetal Neonatal Med 33: 2797-2804.

16. Nishimura A, Fujita Y, Katsuta M, Ishihara A, Ohashi K, et al. (2015) Paternal postnatal depression in Japan: an investigation of correlated factors including relationship with a partner. BMC Pregnancy and Childbirth 15: $1-8$

17. Iwafuji H, Muto T (2007) Casual relationship between ante-and postnatal depression and marital intimacy: from longitudinal research with new parents. Japan J Fam Psychol 21: 34-45.

18. Tokumitsu K, Sugawara N, Maruo K, Suzuki T, Shimoda K, et al. (2020) Prevalence of perinatal depression among Japanese women: a metaanalysis. Ann Gen Psychiatry 19: 1-18.

19. Kitamura T, Takegata M, Haruna M, Yoshida Y, Yamashita H, et al. (2015) The Mother-Infant Bonding Scale: Factor structure and psychological correlates of parental bonding disorders in Japan. Journal of child and family studies 24: 393-401.

This article was originally published in a special issue:

Midwifery and Women's Health

Handled by Editor(s):

Prof. Reiko Sakae

Faculty of Nursing

Shikoku University

Japan 